Canadian

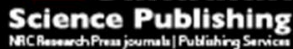

Canadian Geotechnical Journal Revue canadienne de géotechnique

\title{
Pipe-soil interaction model for current-induced pipeline instability on a sloping sandy seabed
}

\begin{tabular}{|r|l|}
\hline Journal: & Canadian Geotechnical Journal \\
\hline Manuscript ID & cgj-2016-0071.R1 \\
\hline Danuscript Type: & Article \\
\hline Complete List of Authors: & $\begin{array}{l}\text { Gao, Fuping; Institute of Mechanics, Chinese Academy of Sciences } \\
\text { Wang, Ning; Institute of Mechanics, Chinese Academy of Sciences } \\
\text { Li, Jinhui; Harbin Institute of Technology Shenzhen Graduate School; The } \\
\text { university of western australia, cofs } \\
\text { Han, Xi-Ting; Tsinghua University; Institute of Mechanics, Chinese } \\
\text { Academy of Sciences }\end{array}$ \\
\hline Keyword: & $\begin{array}{l}\text { Submarine pipeline, On-bottom stability, Sandy seabed, Analytical study, } \\
\text { Pipe-soil interaction }\end{array}$ \\
\hline
\end{tabular}




\section{Pipe-soil interaction model for current-induced pipeline instability on a sloping sandy seabed ${ }^{*}$}

Fu-Ping Gao, Ning Wang, Jinhui Li, Xi-Ting Han

Fu-Ping Gao (Corresponding author), Professor, Institute of Mechanics, Chinese Academy of Sciences, Beijing 100190, China. Email: fpgao@imech.ac.cn; Tel: +86 10 82544189, Fax: +861062561284

Ning Wang, PhD student, Institute of Mechanics, Chinese Academy of Sciences, Beijing 100190, China. Email: wangn07@ 163.com

Jinhui Li, Associate Professor, Harbin Institute of Technology Shenzhen Graduate School, Shenzhen 518055, China. Previously Lecturer, Centre for Offshore Foundation Systems, University of Western Australia, WA 6009, Australia. Email: lisa.li@uwa.edu.au

Xi-Ting Han, Research Engineer, Tsinghua University, Beijing 100084, China. Previously Master Student, Institute of Mechanics, Chinese Academy of Sciences, Beijing 100190, China. Email: hanxt@mail.tsinghua.edu.cn

\footnotetext{
* Revised manuscript to Canadian Geotechnical Journal: Special Issue on Pipeline Geotechnics for review
} 


\section{$1 \quad$ Abstract}

2 As the offshore exploitation moving to deeper waters, ocean currents would become

3 more prevailing hydrodynamics on pipelines, and meanwhile the sloping seabed is

4 always encountered. The prediction of lateral soil resistance is vital in evaluating the

5 pipeline on-bottom stability. Unlike the previous pipe-soil interaction models mainly

6 for horizontal seabed conditions, a pipe-soil interaction model for current-induced

7 downslope and upslope instabilities is proposed by using limit equilibrium approach.

8 The Coulomb's theory of passive earth pressure for the sloping seabed is

9 incorporated in the derivation. The model verification with the existing full scale

10 tests shows a good agreement between the experimental results and the predicted

11 ones. Parametric study indicates that the effect of slope angle on the pipeline lateral

12 soil resistance is significant in the examined range of the slope angle from $-15^{0}$ to

$1315^{0}$. The critical pipeline embedment and the corresponding passive-pressure

14 decreases approximately linearly with increasing slope angle.

15 Key words: Submarine pipeline; On-bottom stability; Sandy seabed; Analytical 16 study; Pipe-soil interaction; Sloping seabed 


\section{Introduction}

Lateral soil resistance is one of the fundamental issues in submarine pipeline on-bottom stability design for the hydrodynamic loading conditions in offshore environments (Wagner et al. 1989; Det Norske Veritas 2010). The behavior of the pipeline on-bottom instability in ocean environments is a complex phenomenon, involving significant flow-soil-structure interaction. Unlike the conventional foundations of structures, on-bottom pipelines can tolerate moderate movements across the seabed without exceeding a limit state, except where they are constrained by wellheads, other connections or obstructions on the seabed (Randolph and Gourvenec 2011). As the oil and gas exploitation moving into deeper waters, ocean current becomes one of the prevailing hydrodynamic loads on submarine pipelines. Besides the usual steady current, a turbidity current fast-moving down a slope can incise and erode continental margins and even cause serious damage to engineering structures. The interaction of internal waves with the seabed is another significant source of near bed currents (Boczar-Karakiewicz et al. 1991). It is noted that the submarine pipelines are more preferred to be laid directly on the seabed (seldom buried artificially) in deeper waters. Meanwhile, the submarine slopes are always encountered, e.g. at the continental slopes in South China Sea (Liu et al. 2002). As such, an improved understanding of the mechanism on current-induced instability of unburied pipelines on a sloping seabed would be beneficial to offshore engineering practices.

When ocean currents are in perpendicular to the axis of a horizontal pipeline 
50 Fig. 1. Illustration of the current-induced pipeline lateral instability on a sloping

which is partially-embedded in the sloping seabed with certain slope angle $(\alpha)$, the flow-induced pipeline on-bottom instability can be regarded as a plane strain problem (see Fig. 1). There normally exists a balance between hydrodynamic loads (including drag force, $F_{\mathrm{Du}}$, and lift force, $F_{\mathrm{L}}$ ), the submerged weight of the pipeline, $W_{\mathrm{s}}$, and the soil resistance, $F_{\mathrm{Ru}}$. If the soil lateral resistance to the pipeline could not balance the hydrodynamic loads and the submerged weight, the pipeline would break out from its original locations, i.e. the lateral on-bottom instability occurs. Thus, an accurate prediction of the ultimate lateral soil resistance is vital for properly evaluating the on-bottom stability of the pipeline partially-embedded on a sloping seabed. seabed: (a) Downslope instability; (b) Upslope instability

The conventional interfacial frictional theory (i.e. Coulomb friction model) was ever suggested to predict the lateral soil resistance of the pipeline (Lyons 1973). Previous pipe-soil interaction tests (Wagner et al. 1989; Brennodden 1989; Gao et al. 2007,2011 ) showed that the loading history that increased the pipe penetration led to a notable increase of the lateral on-bottom stability. The soil berm ahead of the pipe provides passive resistance, which governs the lateral pipe-soil interaction force (White and Cheuk 2008; Youssef et al. 2013). Hence, the soil resistance is far more complex than the simple interfacial friction that calculated using the conventional Coulomb friction model. A literature review on physical modeling of pipeline 
on-bottom stability can be referenced in Gao et al. (2012). The existing test data indicated that the lateral resistance was significantly dependent on pipe penetration and soil strength.

An empirical pipe-soil model by Wagner et al. (1989) has been adopted for the dynamic lateral stability analysis in the current DNV Recommended Practice for on-bottom stability design of submarine pipelines (Det Norske Veritas 2010). Their model was based on the results of a series of pipe-soil interaction tests. The lateral resistance $\left(F_{\mathrm{R}}\right)$ was estimated by the model including the following two components, i.e. a sliding-resistance component ( $\left.F_{\mathrm{Rf}}\right)$ plus a passive-pressure component ( $\left.F_{\mathrm{Rp}}\right)$ :

$$
F_{\mathrm{R}}=\underbrace{\mu_{0}\left(W_{\mathrm{S}}-F_{\mathrm{L}}\right)}_{F_{\mathrm{Rf}}}+\underbrace{\beta_{0} \gamma^{\prime} A_{0.5}}_{F_{\mathrm{Rp}}} \quad \text { (for a horizontally flat sandy seabed) }
$$

where $\mu_{0}$ is the sliding resistance coefficient, which was set as 0.60 for the pipe on sands; $W_{\mathrm{S}}$ is the submerged weight of the pipe per unit length (in $\mathrm{kN} / \mathrm{m}$ ); $F_{\mathrm{L}}$ is the hydrodynamic lift force on the pipe per unit length (in $\mathrm{kN} / \mathrm{m}$ ); $\gamma^{\prime}$ is the effective (buoyant) unit weight of the sand $\left(\right.$ in $\left.\mathrm{kN} / \mathrm{m}^{3}\right) ; A_{0.5}$ is a characteristic area which can be calculated from the initial estimated penetration, i.e. one half of the vertical cross sectional area of the soil displaced by the partially-embedded pipe (in $\left.\mathrm{m}^{2}\right) ; \beta_{0}$ is a dimensionless empirical coefficient for the soil passive pressure, which is relative to the sand density and the loading history. For the simple monotonic lateral loading, the values of $\beta_{0}$ were recommended empirically with a wide range, from " 38 " for sands with $\gamma^{\prime}<8.6 \mathrm{kN} / \mathrm{m}^{3}$ to "79" for sand with $\gamma^{\prime}>9.6 \mathrm{kN} / \mathrm{m}^{3}$. It should be noticed that a direct sum in the scalar form of the sliding-resistance and the passive-pressure components (see eq. (1)) was not appropriate for describing the 
actual pipe-soil interactions. In the existing empirical lateral pipe-soil interaction models (e.g. the aforementioned model (eq. (1)), and an energy-based pipe-soil interaction model by Brennodden et al. (1989)), the ultimate lateral soil-resistance to the partially-embedded pipeline has not been well understood.

Historically, plasticity theory has been used for calculating the lateral earth pressure on conventional retaining walls, which is a central issue in the analysis of retaining structures. In the plasticity analysis, a zone of soil is assumed to reach its plastic equilibrium such that plastic collapse occurs. This plastic soil zone slips relative to the rest of soil mass along the slip surface, where the peak soil strength is assumed to be mobilized (Osman and Bolton 2004). The full range of soil strengths can be expressed in terms of the variation of shearing resistance angle $(\varphi)$ with density and confining pressure (Bolton 1986). As is well-known, plasticity theory can be employed for collapse load calculation, whereas elasticity theory is usually used to predict strain or displacement. Limit equilibrium approach is efficient for determination of passive pressure coefficients for retaining walls (Patki et al. 2015). Numerical study by Potts and Fourie (1986) showed that the effect of Young's modulus distribution on the overall stability of a conventional retaining wall (characterized with passive or active pressure coefficients) appears to be negligible. Force-resultant plasticity models for the combined vertical and horizontal loading conditions have been successively developed and employed for simulating the pipeline on-bottom responses (e.g., Zhang et al. 2002; Hodder and Cassidy 2010). These numerical models were based on the plasticity theory and verified by series of 
sideswipe tests of a partially embedded pipeline on calcareous sands. The behaviors of the entire pipe foundation were encapsulated by relating the resultant forces to the corresponding displacements of the pipeline.

The previous numerical and the empirical analyses were mainly for the condition of horizontally flat seabed, which is typical for the shallow continental shelf regions. As the offshore engineering practice moving to the deeper continental slope regions, the influence of the seabed slope should be taken into consideration for evaluating the ultimate lateral-resistance of the submarine pipelines. In the existing theoretical investigations on the pipeline lateral stability, the influence of the slope angle of the seabed has not been considered yet.

In this study, an improved analytical pipe-soil interaction model is developed on the basis of the passive soil pressure theory to assess the lateral instability of submarine pipelines on a sloping sandy seabed. The developed model is verified by the existing experimental and numerical results. The effect of seabed slope angle on the lateral on-bottom stability is further investigated.

\section{Critical Soil Resistance for a Partially-embedded Pipeline}

\section{Assumptions and application scopes}

For the pipeline-soil interaction system subject to ocean current loading, a proper evaluation of the soil resistance is key to evaluate the pipeline on-bottom stability, especially when a sloping seabed is encountered. If the hydrodynamic loads are large enough to induce the pipeline instability, the consequence of the lateral pipeline movement is to bring the neighboring soil of the sloping seabed from a quasi- $\mathrm{K}_{0}$ 
state to a passive limiting equilibrium state. In this analytical investigation, in order to derive a reasonable analytical solution for evaluating the soil resistance to an unburied pipeline, the main assumptions and application scopes are discussed and listed as follows.

As the rigidity of a submarine pipeline is normally much larger than that of the soils, it would be reasonable to assume the pipeline as a rigid shallow foundation. In the offshore fields, the submarine pipeline diameter $(D)$ normally ranges from several inches to around 40 inches $(\sim 1.0 \mathrm{~m})$. The examined embedment-to-diameter ratio $\left(e_{0} / D\right)$ is in the range of 0 to 0.5 . Due to the constraints from the pipeline ends linking with the subsea well-heads and/or from the locking blocks, the anti-rolling condition is under consideration, i.e. the pipeline may move in parallel or normal to the seabed surface, but the free rolling is prohibited.

The hydrodynamics on the partially-embedded pipeline under the action of ocean currents include the drag force $F_{\mathrm{D}}$ (parallel to the seabed surface) and the lift force $F_{\mathrm{L}}$ (upward perpendicular to the seabed surface) (see Fig. 1), which can be calculated with the Morison equations (Morison et al. 1950), i.e.

$$
\begin{aligned}
& F_{\mathrm{D}}=\frac{1}{2} C_{\mathrm{D}} \rho_{\mathrm{w}} D U^{2} \\
& F_{\mathrm{L}}=\frac{1}{2} C_{\mathrm{L}} \rho_{\mathrm{w}} D U^{2}
\end{aligned}
$$

where $C_{\mathrm{D}}$ and $C_{\mathrm{L}}$ are the drag and the lift force coefficient, respectively; $\rho_{\mathrm{w}}$ is the mass density of the water (in $\mathrm{kg} / \mathrm{m}^{3}$ ); $D$ is the outer diameter of the submarine pipeline; $U$ is the velocity of the ocean currents (in $\mathrm{m} / \mathrm{s}$ ). As recommended by Jones (1978), the effective hydrodynamic coefficients $\left(C_{\mathrm{D}}\right.$ and $\left.C_{\mathrm{L}}\right)$ for a pipeline resting on 
150

151

152

the seabed $(e / D=0)$ can be determined with their correlations with the values of Reynolds number $(R e=U D / v$ is the ratio of inertia force to viscous force; $v$ is the kinematic viscosity of water (in $\mathrm{m}^{2} / \mathrm{s}$ ). $v \approx 1.5 \times 10^{-6} \mathrm{~m}^{2} / \mathrm{s}$ for water at $5^{\circ} \mathrm{C}$ ). With Re increasing from $3.0 \times 10^{4}$ to $1.0 \times 10^{6}$, both the drag coefficient $C_{\mathrm{D}}$ and the lift coefficient $C_{\mathrm{L}}$ decrease gradually to constant values with similar trends (also see Gao et al. 2011).

The above Morison equations with the modification of drag and lift coefficients by Jones (1978) may provide a convenient approach for the pipeline hydrodynamics calculation. Such a conventional calculation approach is semi-empirical, in which the force coefficients were determined from the tests. Soedigdo et al. (1999) proposed a more sophisticated analytical model (i.e. Wake II model) for predicting the near-wall pipeline hydrodynamics in waves, in which the wake velocity correction was derived based on a closed-form solution to the linearized NavierStokes model for oscillatory flow and the hydrodynamic forces coefficients were determined based on start-up effects. Note that in those models for hydrodynamic loads calculations, the penetration effect has not been taken into account. It was observed by Jacobsen et al. (1989) that while the pipeline partially penetrating into the seabed, the hydrodynamic loads are decreased gradually, noting that the lift coefficient is influenced slightly when the embedment-to-diameter ratio is less than 0.10. The recommended reduction factors due to pipeline penetration/embedment for the hydrodynamic loads can be referenced in Det Norske Veritas (2010).

For the current-induced pipeline on-bottom stability on the sloping seabed with 
172 a slope angle $(\alpha)$, the following force equilibrium equations should be satisfied in

173 both directions of parallel $(x)$ and perpendicular $(y)$ to the seabed surface, 174 respectively (Fig. 1):

175

176

177

$$
\begin{aligned}
& F_{\mathrm{R}}=F_{\mathrm{D}}-W_{\mathrm{S}} \sin \alpha \text { (in } x \text { direction) } \\
& F_{C}=W_{\mathrm{S}} \cos \alpha-F_{\mathrm{L}} \text { (in } y \text { direction) }
\end{aligned}
$$

where $F_{\mathrm{C}}$ is the prop force of the seabed to the unburied pipeline, i.e. the net normal load in between the pipeline and the underlying soil.

The sandy seabed is taken into account in this analytical investigation. Sand sediments can be deposited at different rates, resulting in a range of initial densities which influence subsequent behaviors (Potts and Zdravkovic 1999). As a shallow foundation, the partially-embedded pipeline can be supposed as a retaining structure. While losing lateral stability, the pipeline pushing the frontal sand ahead can be regarded as a quasi-static process, where a fully drained condition is basically satisfied in the shallow sand layer.

A two-dimensional (2-D) plane strain elasto-plastic Finite Element (FE) model was recently proposed by Han (2012) to predict the pipeline-soil interaction behavior on the sloping seabed. A series of FE analyses (Han, 2012) indicated that the plastic failure zone developed in the proximity of the pipeline when losing lateral stability is quite similar to that in the previous analyses on the retaining walls (Potts and Zdravkovic 2001). The details for the typical numerical simulation can be seen in the latter section for the model validation. This can also provide a reasonable confirmation of the empirical pipe-soil interaction model based on the test 
194

195

196

197

198

199

200

observations by Wagner et al. (1989), i.e. the total soil resistance includes the sliding-friction and the passive-pressure components.

The submarine slopes are always encountered in the offshore pipeline engineering, which are generally gentler than the typical slopes on land. In this study, the influence of slope angle on the pipeline on-bottom instability is examined analytically with the proposed model. Two typical on-bottom instabilities are involved, i.e. (1) Type-I: downslope instability and (2) Type-II: upslope instability. The effects of slope angle will be investigated in the later section.

Based on the aforementioned analyses and discussions, in the proposed analytical model, the composite failure surface comprises a sliding-friction segment and a passive-pressure segment. The passive pressure is to be calculated with the well-known Coulomb's theory of passive earth pressure for the soil slopes at a constant angle to the horizontal (see Craig 2004; Chen and Liu 1990). In this study, the examined absolute values of the slope angle are in the range of $0 \sim 15^{0}$, which covers the common submarine in-situ conditions.

In this theoretical derivation, the plane-strain condition is under consideration, i.e. the pipeline is aligned with the bathymetric contours of the sloping seabed, and the current is flowing perpendicularly to the pipeline. For more general cases with oblique flow and run-off elevation laying, the conditions would be three-dimensional in nature and the axial flow-pipe-soil interaction effects would emerge, for which the present theoretical solutions could not be extended directly and should be further examined. 
217 As previously stated, the Coulomb's theory of passive earth pressure is incorporated

218 in the present analytical model. The composite failure surface for the lateral pipe-soil

219 interaction on a sloping seabed (see Fig. 2 and Fig. 3) includes a sliding-friction

220 segment (denoted as "segment-DB") and a passive-pressure segment

221 ("segment-BC"). Fig. 2 and Fig. 3 illustrate the geometry of failure mechanism and

222 the force triangles for the downslope instability and those for the upslope instability,

223 respectively. Along both segments (segment-DB and segment-BC), the shear

224 strength of the soil is fully mobilized while the pipeline losing lateral stability.

Fig. 2. Downslope instability of a submarine pipeline: (a) Geometry of failure

mechanism; (b) Triangle of the forces on the wedge-ABD (shaded area in Fig

2(a))

Fig. 3. Upslope instability of a submarine pipeline: (a) Geometry of failure

mechanism; (b) Triangle of the forces on the wedge-ABD (shaded area in Fig

Based on the Coulomb's theory of passive earth pressure, the shearing

234 resistance on the segment-BC and the weight of the wedge- $\mathrm{ABC}$ would be balanced

235 by the thrust force $\left(E_{1}\right)$ on a virtual retaining wall-AB. The length of the virtual

236 retaining wall-AB has the same value with the pipeline embedment $\left(e_{0}\right)$. As

237 illustrated in Fig. 2(a) and Fig. 3(a), the retaining wall-AB is supposed perpendicular 
to the seabed surface, and the sliding-friction segment-DB is parallel to the seabed surface (i.e. perpendicular to the wall-AB).

Choosing the wedge-ABD (the shaded areas in Fig. 2(a) and Fig. 3(a)) as the analysis object, the main forces acting on the wedge-ABD at failure for these two types of instabilities include: (1) The passive earth pressure on the virtual retaining wall-AB, the total force of which, as stated above, is denoted as the thrust force $E_{1}$ ); (2) The sliding-friction force $\left(E_{2}\right)$ on the segment-DB, with an inclination angle $(\varphi)$ to the normal; (3) The submerged weight of the wedge-ABD; and (4) The total pipe-soil interfacial force $(P)$. The details of the calculation for these forces are as follows.

The passive earth pressure $E_{1}$ can be calculated with Coulomb's theory of passive earth pressure for the soil surface slopes (see Craig 2004):

$$
E_{1}=\frac{1}{2} \gamma^{\prime}\left(e_{0} \cos \alpha\right)^{2} K_{\mathrm{p}}
$$

where " $e_{0} \cos \alpha$ " is the vertical component of the length of the wall-AB (see Fig. 2(a) or Fig. 3(a)); $K_{\mathrm{p}}$ is the passive pressure coefficient for the sloping soil with a constant slope angle $(\alpha)$ :

$$
K_{\mathrm{p}}=\left[\frac{\cos \left(\varphi+\alpha^{\prime}\right) / \cos \left(\alpha^{\prime}\right)}{\sqrt{\cos \left(\varphi^{\prime}-\alpha^{\prime}\right)}-\sqrt{\sin \left(\varphi+\varphi^{\prime}\right) \sin (\varphi+\alpha) / \cos \left(\alpha-\alpha^{\prime}\right)}}\right]^{2}
$$

in which, the internal friction angle of the sand $(\varphi)$ is the drained (effective stress) shear strength parameter for the sand; $\alpha^{\prime}$ is the angle between the virtual retaining wall-AB and the vertical; $\varphi^{\prime}$ is the mobilized friction angle at the wall-AB. As for a sloping seabed with slope angle $\alpha$, the virtual retaining wall-AB is supposed to be 
259 inclined with an inclination angle $\alpha^{\prime}$. Both angles ( $\alpha$ and $\left.\alpha^{\prime}\right)$ are included in the

260 expression of $K_{\mathrm{p}}$ by eq. (5). Considering the examined values of $\alpha^{\prime}$ range from

$261-15^{0} \sim 15^{0}$, the values of $\alpha^{\prime}$ can be regarded as the same with the slope angle $\alpha$ for

262 the purpose of simplification in the derivation. The friction angle along the retaining

263 wall $\left(\varphi^{\prime}\right)$ is always partially mobilized, whose values in the passive case are usually

264 less than $\varphi / 3$ (Craig 2004). As such, choosing the value of $\varphi^{\prime}$ as nil would be

265 conservative for evaluating the lateral soil resistance to the partially-embedded

266 pipeline. Submitting $\alpha^{\prime}=\alpha$ and $\varphi^{\prime} \approx 0$ into eq. (5), then

267

$$
K_{\mathrm{p}}=\left[\frac{\cos (\varphi+\alpha) / \cos (\alpha)}{\sqrt{\cos (\alpha)}-\sqrt{\sin (\varphi) \sin (\varphi+\alpha)}}\right]^{2}
$$

Fig. 4 gives the variation of values of the passive pressure coefficient $\left(K_{\mathrm{p}}\right)$ with the

269 slope angle $(\alpha)$ for certain values of the internal friction angle of the sand $\left(\varphi=25^{0}\right.$,

$27030^{\circ}, 35^{\circ}, 40^{\circ}$ and $45^{\circ}$ ). Note that the values of $\alpha$ are positive for the upslope

271 instability, whereas they are negative for the downslope instability. When $\alpha=0$

272 (meanwhile $\varphi^{\prime}=0$ ), the passive pressure coefficient $\left(K_{\mathrm{p}}\right)$ in the Coulomb theory (eq.

273 (6)) is identical to that of the Rankine theory for the case of a vertical wall and a

274 horizontal soil surface, i.e. $K_{\mathrm{p}}=(1+\sin \varphi) /(1-\sin \varphi)$. As shown in Fig. 4, for a certain

275 value of $\varphi$, the values of $K_{\mathrm{p}}$ increase gradually with increasing slope angle $\alpha$ (from

$276-15^{0}$ to $15^{0}$ ). Meanwhile, if the values of $\alpha$ is fixed, the $K_{\mathrm{p}}$ increases gradually with 277 the increase of $\varphi$.

Fig. 4. Variation of the passive pressure coefficient $\left(K_{\mathrm{p}}\right)$ with the slope angle 

Fig. 3(a)) can be calculated with

$$
W_{\mathrm{b}}=\frac{\gamma^{\prime}}{8}\left[4 e_{0}^{2} \frac{1+\cos \theta_{0}}{\sin \theta_{0}}-D^{2}\left(\theta_{0}-\sin \theta_{0}\right)\right]
$$

in which, $\theta_{0}(=\angle \mathrm{AOD}$, see Fig. 2(a) or Fig 3(a)) is a half of the angle of the pipeline penetration:

$$
\theta_{0}=\arccos \left(1-2 \frac{e_{0}}{D}\right)
$$

It should be noticed that the pipe-soil interface is the circular arc-AD (Fig. 2(a) interfacial force $(P)$, the circular arc-AD is simplified as the straight line segment total pipe-soil interfacial force $(P)$ can thereby be derived following the analysis on the forces on the wedge-ABD (Fig. 2 and Fig 3). By using the "law of sines" to the 


$$
\frac{P}{\sin (\angle \mathrm{MNL})}=\frac{F_{\mathrm{MN}}}{\sin (\angle \mathrm{MLN})}
$$

301 in which, $\angle \mathrm{MNL}=\pi / 2+\omega+\varphi ; \quad \angle \mathrm{MLN}(=\pi / 2-(\beta-\delta)-\varphi)=3 \theta_{0} / 4+\delta-\varphi ;$

$302 F_{\mathrm{MN}}$ is the resultant force of $E_{1}$ and $W_{\mathrm{b}}: F_{\mathrm{MN}}=\left(E_{1} \cos \varphi^{\prime}+W_{\mathrm{b}} \sin \alpha\right) / \cos \omega$. Thus,

303 the total pipe-soil interfacial force $P$ can be obtained:

304

$$
P=\frac{\cos (\varphi+\omega)}{\cos (\omega) \sin \left(3 \theta_{0} / 4+\delta-\varphi\right)}\left(E_{1} \cos \varphi^{\prime}+W_{\mathrm{b}} \sin \alpha\right)
$$

where $\delta$ is the inclination angle to the normal for $P$. Note that the signals of $\delta$ are positive for the clockwise of the $P$ in the case of downslope instability (Fig. 2(a)) and for the anti-clockwise of the $P$ in case of upslope instability (Fig. 3(a)), respectively. $\omega$ is the intersection angle between the direction of $F_{\mathrm{MN}}$ to the seabed surface (Fig. 2(b) and Fig 3(b)), which can be calculated by

$$
\omega=\arctan \left(\frac{E_{1} \sin \varphi^{\prime}-W_{\mathrm{b}} \cos \alpha}{E_{1} \cos \varphi^{\prime}+W_{\mathrm{b}} \sin \alpha}\right)
$$

When the friction angle along the retaining wall- $\mathrm{AB}$ approaching zero, i.e. the thrust force $E_{1}$ is acting approximately normally to the retaining wall, eq. (12) can then be expressed as

$$
\omega \approx \arctan \left(\frac{-W_{\mathrm{b}} \cos \alpha}{E_{1}+W_{\mathrm{b}} \sin \alpha}\right) \quad\left(\text { for } \varphi^{\prime} \approx 0\right)
$$

Once the total pipe-soil interfacial force $(P)$ is predicted by eq. (11), the critical (maximum) lateral soil resistance $\left(F_{\mathrm{R}}\right)$ and the corresponding prop force $\left(F_{\mathrm{C}}\right)$ for the pipeline instability on the sloping seabed can be further obtained:

$$
\begin{aligned}
& F_{\mathrm{R}}=P \cos (\beta-\delta) \\
& F_{\mathrm{C}}=P \sin (\beta-\delta)
\end{aligned}
$$


320

321

322

324

325

326

327

328

The force equilibrium conditions (eqs. (3a) and (3b)) are utilized to identify the unique failure surface by solving these equation group. Submitting eqs. (13a) and (13b) into the force equilibrium equations eqs. (3a) and (3b), then

$$
\tan (\beta-\delta)=\frac{W_{\mathrm{S}} \cos \alpha-F_{\mathrm{L}}}{F_{\mathrm{D}}-W_{\mathrm{S}} \sin \alpha}
$$

Furthermore, submitting eq. (9) into eq. (14), the geometry relationship between the pipeline penetration and the direction for total pipe-soil interfacial force can be established:

$$
\frac{3}{4} \theta_{0}+\delta=\arctan \left(\frac{F_{\mathrm{D}}-W_{\mathrm{S}} \sin \alpha}{W_{\mathrm{S}} \cos \alpha-F_{\mathrm{L}}}\right)
$$

If the values of the following parameters for the soil and the pipeline are known, i.e. $\alpha, \varphi, D, \gamma^{\prime}, W_{\mathrm{s}}$ and $U$, then the two unknown values of $\theta_{0}$ and $\delta$ can be determined by eq. (15) together with one of the two eqs. (3a) and (3b). When the value of $\theta_{0}$ is obtained, the pipeline embedment $\left(e_{0}\right)$ can be further calculated by eq. (8). In the engineering practice, this calculated value of $e_{0}$ could be treated as the critical (minimum) pipeline embedment for on-bottom stability (termed as " $e_{\mathrm{cr}}$ ").

Similar to the above 'scene representation', if the value of the pipeline embedment $\left(e_{0}\right)$ is given ( $W_{\mathrm{s}}$ is not known in advance), the values of $W_{\mathrm{s}}$ together with $\delta$ can also be determined by solving the same equation group, i.e. eqs. (15) and (3a) or (3b).

Note that the signals of $\delta$ can be either positive or negtive. Nevertheless, the absolute values of the pipe-soil interfacial friction angle $(|\delta|)$ should be no larger than its critical value ( $\delta_{\text {crit }}$ ), i.e. $|\delta| \leq \delta_{\text {crit }}$; Otherwise, the partially-embedded 
341 pipeline would breakout from its in-place location through the pipe-soil interfacial

342 slippage. In accordence with clasical plasticity theory, the critical pipe-soil

343 interfacial friction angle can be evaluated with

$$
\delta_{\text {crit }}=\arctan \left(\frac{\sin \varphi \cos v}{1-\sin \varphi \sin v}\right)
$$

345 in which, $v$ is the angle of soil dilation. Eq. (16) is a direct consequence of the

346 assumption of conincidence of stress and the plastic strain increment directions, and

347 that the soil is plastic immediately adjacent to the wall (pipe-soi interface) (Potts and

348 Fourie 1986; Lee and Herington 1972).

\section{Three components of the critical soil resistance}

350 As aforementioned, in the pipe-soil interaction model (Wagner et al. 1989), the lateral resistance $F_{\mathrm{R}}$ to the submarine pipeline on a horizontal sandy seabed $(\alpha=0)$ was evaluated by the form of eq. (1). As discussed in the introduction, their model is essentially empirical, with high uncertainty in the empirical coefficient $\beta_{0}$ for evaluating the passive pressure. Unlike the previous model, the present pipe-soil interaction model for a sloping sandy seabed may provide an explicit expression of

$$
F_{\mathrm{R}}=\underbrace{0.5 \gamma^{\prime}\left(e_{0} \cos \alpha\right)^{2} \cos \left(\varphi^{\prime}\right) K_{\mathrm{p}}}_{F_{\mathrm{Rp}}}+\underbrace{E_{2} \sin \varphi}_{F_{\mathrm{Rf}}}+\underbrace{W_{\mathrm{b}} \sin \alpha}_{F_{\mathrm{RW}}}
$$

in which $F_{\mathrm{Rp}}, F_{\mathrm{Rf}}$ and $F_{\mathrm{Rw}}$ are the passive-pressure, the sliding-friction, and the additional submerged weight (from the wedge-ABD) components, respectively; $K_{\mathrm{p}}$ and $W_{\mathrm{b}}$ can be calculate by eq. (6) and eq. (7), respectively; the total sliding-friction

$361 E_{2}$ along the bottom of the wedge-ABD (Figs. 2(a) and 3(a)) can be calculated in 
362

363

364

accordance with the law of sines for the forces of triangle ( $\triangle \mathrm{LMN}$; see Fig. 2(b) and 3(b)):

$$
\frac{F_{\mathrm{MN}}}{\sin \angle \mathrm{MLN}}=\frac{E_{2}}{\sin \angle \mathrm{LMN}} \text {, i.e. } \frac{\left(E_{1} \cos \varphi^{\prime}+W_{\mathrm{b}} \sin \alpha\right) / \cos \omega}{\sin (\pi / 2+\delta-\beta-\varphi)}=\frac{E_{2}}{\sin (\beta-\delta-\omega)}
$$

Thus, the total sliding-friction $E_{2}$ can be expressed as

$$
E_{2}=\frac{\sin (\beta-\delta-\omega)}{\cos (\omega) \cos (\beta-\delta+\varphi)}\left(E_{1} \cos \varphi^{\prime}+W_{\mathrm{b}} \sin \alpha\right)
$$

In the following sections, the verification and mechanism analysis will be made on the pipe-soil interaction, in which the force components of the critical soil resistance will be presented in detail.

\section{Verification of the Proposed Model}

The proposed pipe-soil interaction model is verified with the existing results of a series of full scale tests by Wagner et al. (1989). Table 1 gives the detailed comparisons between the existing test results and the predictions with the present model for pipe-soil interactions on flat sand-beds.

Table 1 lists the results of 10 series of pipe-soil interaction tests on a loose medium/coarse sand, and 5 series of tests on dense medium/coarse sand for the comparison with the predicted values. In the reference (Wagner et al. 1989), the information on the internal friction angle $(\varphi)$ was not provided, but values of the relative density for the test sands were given. As listed in Table 1, the values of $\varphi$ are evaluated by considering the concept of relative dilatancy index (Bolton 1986), i.e. for a plane strain problem: 
382

383

384

$$
\varphi \approx \varphi_{\text {crit }}+5 I_{\mathrm{R}}
$$

where $\varphi_{\text {crit }}$ is the critical state angle of shearing resistance of sands (the recommended $\varphi_{\text {crit }}=35^{\circ}$ for quartz sands); $I_{\mathrm{R}}$ is the relative dilatancy index: $I_{\mathrm{R}}=D_{\mathrm{r}}\left(10-\ln p^{\prime}\right)-1$, in which $D_{\mathrm{r}}$ is the relative density of sands, $p^{\prime}$ is the mean effective stress (in $\mathrm{kPa}$ ). In addition, those pipe-soil interaction tests mainly involved monotonic and cyclic loadings. Note that in their cyclic loading tests, the oscillations were applied in advance, which were only to obtain the additional pipe penetration. In the table, $e_{\mathrm{cr}} / D$ refers to the ratio of the total embedment (including initial embedment and additional penetration) to the pipe diameter. The breakout loads was measured to obtain the values of $F_{\mathrm{R}}\left(=F_{\mathrm{D}}\right.$ for the case of horizontal seabed). The values of " $W_{\mathrm{S}}-F_{\mathrm{L}}$ " are the net vertical prop loads between the pipe and the underlying sand.

As aformentioned, if the parameters for the sand and the pipeline (i.e. $\varphi, D$, $\gamma^{\prime}, W_{\mathrm{s}}, F_{\mathrm{D}}$ and $\left.F_{\mathrm{L}}\right)$ are given, the critical value of $\theta_{0}$ for the pipeline losing on-bottom stability can be determined by eq. (15) and one of the two eqs. (3a) and (3b). When the value of $\theta_{0}$ is obtained, the corresponding critical pipeline embedment ratio $\left(e_{\mathrm{cr}} / D\right)$ can be calculated by eq. (8). With present model, the passive-pressure and sliding-friction components $\left(F_{\mathrm{Rp}}\right.$ and $\left.F_{\mathrm{Rf}}\right)$ of the total lateral soil resistance $\left(F_{\mathrm{R}}\right)$ can be easily identified and calculated by eq. (17). The predicted values of $F_{\mathrm{Rp}}$ and $F_{\mathrm{Rf}}$ are also listed in the right two columns in Table 1.

Fig 5 gives the comparison of the predicted critical pipeline embedment-to-diameter ratio with the experimental results. The comparision 
404 indicates that the predictions by the present model and the measured values by 405 Wagner et al. (1989) are generally in good agreement. As shown in Fig. 5, there 406 exists some scattering in the data for the conditions of shallow embedment or light 407 submerged weight of pipelines (see Table 1), where the passive-pressure 408 component is less dominant compared to the contributions from the sliding-fricion 409 mechanism. Except for those shallow embedments, the predictions are in general 410 larger than the experimental results (Fig. 5), which may be attributed to that the 411 effect of soil heave was not taken into account in the present model. This may imply 412 the proposed model would be somewhat conservative for predicting the soil lateral 413 resistance.

414 An alternative approach is performed by finite element analysis (FEA) to study 415 the soil-structure interaction (Potts and Fourie 1986). As stated in the previous 416 section, a 2-D plane strain elasto-plastic FE model proposed by Han (2012) was 417 employed for predicting the pipeline-soil interaction behavior on the sloping seabed. 418 Fig. 6 shows the FE results of the case study for the plastic zones around 419 partially-embedded pipelines while losing lateral instability on a sloping sand-bed $420 \quad\left(D=0.5 \mathrm{~m}, e_{0} / D=0.2, W_{\mathrm{s}}=1.568 \mathrm{kN} / \mathrm{m}, \mu=0.3, \varphi=30^{0}\right)$. As illustrated in Fig. 6, 421 for both the downslope instability $\left(\alpha=-10^{\circ}\right)$ and the upslope instability $\left(\alpha=10^{\circ}\right)$, 422 the plastic yielding zones that developed in the proximity of the partially-embedded 423 pipeline hold typical characteristics of retaining structures. It was observed that the 424 plastic yielding zones were close to the pipeline bottom and protruded gradually to 425 the soil surface. The passive failure was clearly identified by the plastic strain 
426

427

development in these plots. Such observations (Figs. 6(a) and 6(b)) in the numerical modeling facilitate the construction of the failure modes (Figs. 2(a) and 3(a)) in the present analyses.

present model for pipe-soil interactions on flat sand-beds.

Fig. 5. Comparison of the predicted critical pipeline embedment $\left(e_{\mathrm{cr}} / D\right)$ with the experimental results

Fig. 6. FE results of plastic zones around partially-embedded pipelines while losing lateral instability on a sloping sand-bed $\left(D=0.5 \mathrm{~m}, e_{0} / D=0.2, W_{\mathrm{s}}=\mathbf{1 . 5 6 8}\right.$ kN/m, $\varphi=3^{0}$ ): (a) Downslope instability $\left(\alpha=-10^{\circ}\right)$; (b) Upslope instability ( $\alpha$ $\left.=10^{\circ}\right)$

It should be noticed that the instability of a submarine pipeline under the action of waves or currents is frequently accompanied by local scour or liquefaction of the soil (Gao et al. 2002; Teh et al. 2003; Gao et al. 2007). As previously pointed by Palmer (1996), the sediment transport of the seabed surface layer can be significant under the extreme conditions in the offshore fields. There exists a non-linear relationship between the non-dimensional critical flow velocity (Shields number) and the particle diameter of the sediments (Chien and Wan, 1999). Therefore, in the pipe-soil interaction analysis, the seabed mobility should be well evaluated simultaneously. When the seabed mobility is not predominant, the proposed pipe-soil model can be employed for a satisfactory prediction of the soil resistance. 
448

449

450

451

452

453

454

455

456

457

458

459

460

461

462

463

464

465

466

467

468

469

\section{Effects of Slope Angle}

As aforementioned, the sloping seabed is encountered more frequently in deeper waters. The seabed in the South China Sea holds rich varieties of its topographic feature including the vast continental shelf, the continental slope and deep sea basin.

The seabed slope angle changes much at various locations, e.g., the measured slope angle generally reaches up to 6.7-17.6 degree at the western continental slope of South China Sea (Liu et al. 2002). To investigate the influence of slope angle on the pipeline lateral instability on a sloping seabed, a case study is performed by using the proposed pipe-soil interaction model.

Table 2 gives the input parameters of the pipeline, the sand and the ocean current. The examined slope angle $(\alpha)$ is in the range of $-15^{0} \sim 15^{0}$. Given the value of $\varphi$ and the $\alpha$ range, the variation of passive pressure coefficients can be calculated by eq. (6). As aforementioned, if the values of the parameters listed in Table 2 are known, the values of the critical pipeline embedment $\left(e_{\mathrm{cr}}\right)$ could be predicted using the proposed model.

The predicted results are shown in Figs. 7(a) and 7(b). It is indicated in Fig. 7(a) that the values of $e_{\mathrm{cr}}$ (and $e_{\mathrm{cr}} / D$ ) decreases approximately linearly with the increase in slope angle ( $\alpha$ from $-15^{0}$ to $15^{0}$ ). Fig. 7(b) illustrates the variations of the total soil resistance $\left(F_{\mathrm{R}}\right)$ and its three components $\left(F_{\mathrm{Rp}}, F_{\mathrm{Rf}}\right.$ and $\left.F_{\mathrm{Rw}}\right)$ with the slope angle. It could be found in this figure that, the sliding-friction component $F_{\mathrm{Rf}}$ and the submerged weight component $F_{\mathrm{Rw}}$ change slightly with the variation of the slope angle. Nevertheless, the passive-pressure component $F_{\mathrm{Rp}}$ decreases approximately 
470 linearly with increasing the slope angle, which is accompanied by the significant

471 decrease in the critical embedment. This implies that to keep the submarine pipeline

472 stable under the action of a downslope current, a larger value of pipe embedment $\left(e_{\mathrm{cr}}\right)$

473 is needed to avoid the occurrence of downslope instability, where a higher

474 passive-pressure $\left(F_{\mathrm{Rp}}\right)$ could be mobilized to obtain the required soil resistance.

475

476

477

478

479

480

481

482

483

484

485

486

487

488

489

490

491

Table 2. Input data for case study of the slope angle effect on pipeline lateral

\author{
instability
}

Fig. 7. Effects of the slope angle on the pipeline instability: (a) Variation of critical pipeline embedment with slope angle; (b) Variations of the total soil resistance and its three components with slope angle

\title{
Conclusions
}

As the offshore exploitation shifting from shallow to deep waters, the ocean current would exert the prevailing hydrodynamics on the submarine pipeline. Meanwhile, the sloping seabed would be encountered frequently, especially at the continental slopes. In this study, the ocean current-induced on-bottom stability of a submarine pipeline laid on a sloping sandy seabed is investigated analytically. The main conclusions drawn from this analysis are as follows:

1. Unlike the previous pipe-soil interaction models for the horizontal seabed conditions, a pipe-soil interaction model is proposed for evaluating the lateral soil resistance to a partially-embedded pipeline on a sloping sandy seabed. The 
492 mechanics for the two types of the current-induced pipeline instability are

493 analyzed, i.e. the downslope instability and the upslope instability.

494 2. By using limit equilibrium approach, the analytical expression of the total lateral

495 soil resistance are derived, which is composed of the sliding-friction component,

496 the passive-pressure component, and the component of submerged weight of the

497 carried soil wedge. The Coulomb's theory of passive earth pressure for the

498 sloping soil is incorporated in the derivation. The model verification with the

499 existing full scale tests shows a good agreement between the experimental

$500 \quad$ results and the predictions.

501 3. Parametric study indicates that the effect of slope angle on the pipeline lateral

502 soil resistance is significant in the examined range of the slope angle from $-15^{0}$ to

$503 \quad 15^{0}$. The critical pipeline embedment and the corresponding passive-pressure

504 decreases approximately linearly with increasing slope angle.

\section{Acknowledgements}

506 This work is financially supported by the Major State Basic Research Development

507 Program of China (973 Program) (Grant No. 2014CB046204) and the National

508 Natural Science Foundation of China (Grant Nos. 11232012; 11372319). Helpful

509 discussions with Dr. Wen-Gang Qi and PhD student Yumin Shi are greatly 510 appreciated. 


\section{References}

Boczar-Karakiewicz, B., Bona, J. L., and Pelchat, B. 1991. Interaction of internal waves with the seabed on continental shelves. Continental Shelf Research, 11(8-10): $1181-1197$.

Bolton, M. D. 1986. The strength and dilatancy of sands. Géotechnique, 36(1), 65-78

Brennodden, H., Lieng, J.T., Sotberg, T., and Verley, R.L.P. 1989. An energy-based pipe-soil interaction model. Proceeding of 21st Annual Offshore Technology Conference, OTC 6057, 147-158.

Chen, H.F. and Liu, X.L. 1990. Limit Analysis in Soil Mechanics, Elsevier Science Publishers B.V., Netherlands.

Chien, N. and Wan, Z. 1999. Mechanics of Sediment Transport. ASCE Press, Reston, Virginia.

Craig, R.F. 2004. Craig's Soil Mechanics (Seventh Edition). London \& New York: E \& FN Spon.

Det Norske Veritas 2010. On-Bottom Stability Design of Submarine Pipelines, DNV Recommended Practice DNV-RP-F109.

Gao, F.P., Gu, X.Y., Jeng, D.S., and Teo, H.T. 2002. An experimental study for wave-induced instability of pipelines: the breakout of pipelines. Applied Ocean Research, 24, 83-90.

Gao, F.P., Han, X.T., Cao, J., Sha, Y., and Cui, J.S. 2012. Submarine pipeline lateral 
instability on a sloping sandy seabed. Ocean Engineering, 50, 44-52.

Gao, F.P., Yan, S.M., Yang, B., and Luo, C.C. 2011. Steady flow-induced instability of a partially embedded pipeline: pipe-soil interaction mechanism. Ocean Engineering, $38,934-942$.

Gao, F.P., Yan, S.M., Yang, B., and Wu, Y.X. 2007. Ocean currents-induced pipeline lateral stability. Journal of Engineering Mechanics, 133, 1086-1092.

Han, X.T. 2012. Ocean Current Induced On-bottom Instability of Submarine Pipelines on a Sloping Seabed. Master Thesis, Graduate University of Chinese Academy of Sciences, Beijing, China.

Hodder, M.S., and Cassidy, M.J. 2010. A plasticity model for predicting the vertical and lateral behaviour of pipelines in clay soils. Géotechnique, 60(4): 247-263.

Jacobsen, V., Bryndum, M. B., and Bonde, C. 1989. Fluid loads on pipelines: Sheltered or sliding. Proceedings of Annual Offshore Technology Conference, 1-4 May, 1989, Houston, Texas, Paper No. OTC 6056.

Jones, W. T. 1978. On-bottom pipeline stability in steady water currents. Journal of Petroleum Technology, 30, 475-484.

Lee, I.K. and Herington, J.R. 1972. A theoretical study of the pressure acting on a rigid wall by sloping earth or rock fill. Géotechnique, 22(1), 1-26.

Liu, Z.S., Zhao, H.T., Fan, S.Q., and Chen, S.Q. 2002. Geology of South China Sea. Beijing: Science Press, China. 
Lyons, C.G. 1973. Soil resistance to lateral sliding of marine pipeline. Proceedings of 5th Annual Offshore Technology Conference, OTC1876, 479-484.

Morison, J.R., O’Brien, M.P., Johnson, J.W., and Schaaf, S.A. 1950. The forces exerted by surface waves on piles. Petroleum Transactions, AIME, 189: 149-157.

Osman, A.S., and Bolton, M.D. 2004. A new design method for retaining walls in clay. Can. Geotech. J., 41: 451-466.

Palmer, A. 1996. A flaw in the conventional approach to stability design of pipelines. Proceedings of 19th Annual Offshore Pipeline Technology Conference (OPT96), Amsterdam, 1-9.

Patki, M.A., Mandal, J.N. and Dewaikar, D.M. 2015. Determination of passive earth pressure coefficients using limit equilibrium approach coupled with the Kotter equation. Can. Geotech. J. 52: 1241-1254. dx.doi.org/10.1139/cgj-2014-0351.

Potts, D. M. and Fourie, A. B. 1986. A numerical study of the effects of wall deformation on earth pressures. International Journal for Numerical and Analytical Methods in Geomechanics, 10(4): 383-405.

Potts, D.M., and Zdravkovic, L. 1999. Finite Element Analysis in Geotechnical Engineering: Theory. Thomas Telford Ltd., London.

Potts, D.M., and Zdravkovic, L. 2001. Finite Element Analysis in Geotechnical Engineering: Application. Thomas Telford Ltd., London.

Randolph M F, and Gourvenec, S. 2011. Offshore Geotechnical Engineering. New 
York: Spon Press.

Soedigdo, I.R., Lambrakos, K.F., and Edge, B.L. 1999. Predicton of hydrodynamic forces on submarine pipelines using an improved wake II model. Ocean Eng. 26, $431-462$.

Teh, T.C., Palmer, A.C., and Damgaard, J.S. 2003. Experimental study of marine pipelines on unstable and liquefied seabed. Coastal Engineering, 50, 1-17.

Wagner, D.A., Murff, J.D., Brennodden, H., and Svegen, O.1989. Pipe-soil interaction model. Journal of Waterway, Port, Coastal and Ocean Engineering, ASCE, 115(2), 205-220.

White, D.J., and Cheuk, C.Y. 2008. Modelling the soil resistance on seabed pipelines during large cycles of lateral movement. Marine Structures, 21(1):59-79.

Youssef, B.S., Tian, Y., and Cassidy, M.J. 2013. Centrifuge modelling of an on- bottom pipeline under equivalent wave and current loading. Applied Ocean Research, 40, 14-25.

Zhang, J., Stewart, D.P., and Randolph, M.F. 2002. Modeling of shallowly embedded offshore pipelines in calcareous sand. Journal of Geotechnical and Geoenvironmental Engineering, ASCE, 128, 363-371. 


\section{Table Captions:}

Table 1. Test results by Wagner et al. (1989) and predictions with the present model for pipe-soil interactions on flat sand-beds.

Table 2. Input data for case study of the slope angle effect on pipeline lateral instability 


\section{Figures Captions:}

Fig. 1. Illustration of the current-induced pipeline lateral instability on a sloping seabed: (a) Downslope instability; (b) Upslope instability

Fig. 2. Downslope instability of a submarine pipeline: (a) Geometry of failure mechanism; (b) Triangle of the forces on the wedge-ABD (shaded area in Fig 2(a))

Fig. 3. Upslope instability of a submarine pipeline: (a) Geometry of failure mechanism; (b) Triangle of the forces on the wedge-ABD (shaded area in Fig $3(\mathrm{a}))$

Fig. 4. Variation of values of the passive pressure coefficient $\left(K_{\mathrm{p}}\right)$ with the slope angle $(\alpha)$

Fig. 5. Comparison of the predicted critical pipeline embedment $\left(e_{\mathrm{cr}} / D\right)$ with the experimental results

Fig. 6. FE results of plastic zones around partially-embedded pipelines while losing lateral instability on a sloping sand-bed $\left(D=0.5 \mathrm{~m}, e_{0} / D=0.2, W_{\mathrm{s}}=1.568\right.$ $\mathrm{kN} / \mathrm{m}, \varphi=30^{0}$ ): (a) Downslope instability $\left(\alpha=-10^{\circ}\right)$; (b) Upslope instability $\left(\alpha=10^{0}\right)$

Fig. 7. Effects of the slope angle on the pipeline instability: (a) Variation of critical pipeline embedment with slope angle; (b) Variations of the total soil resistance and its three components with slope angle 


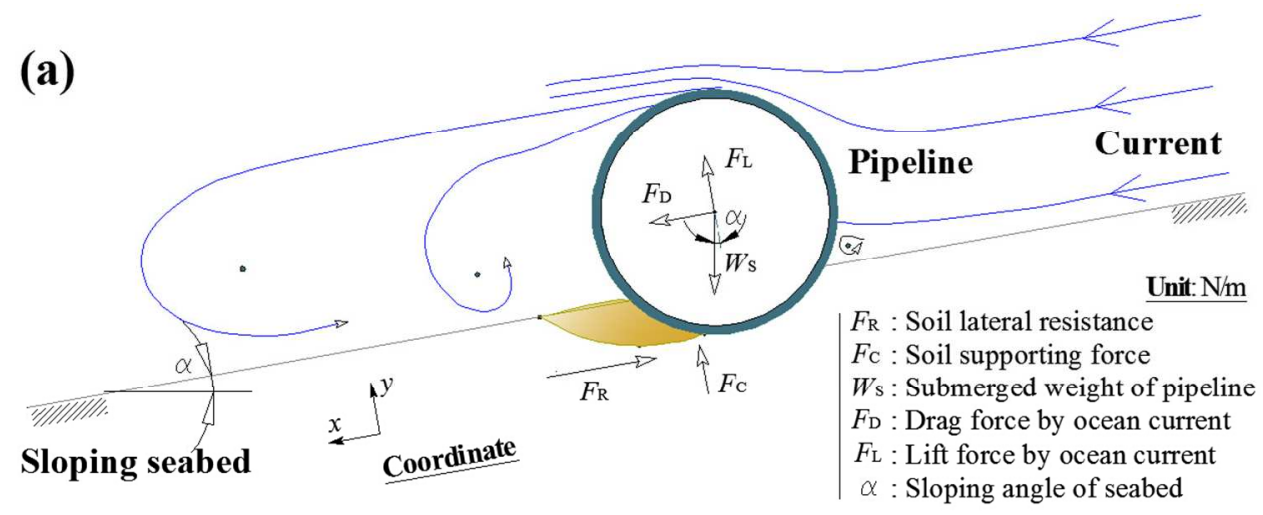

(b)

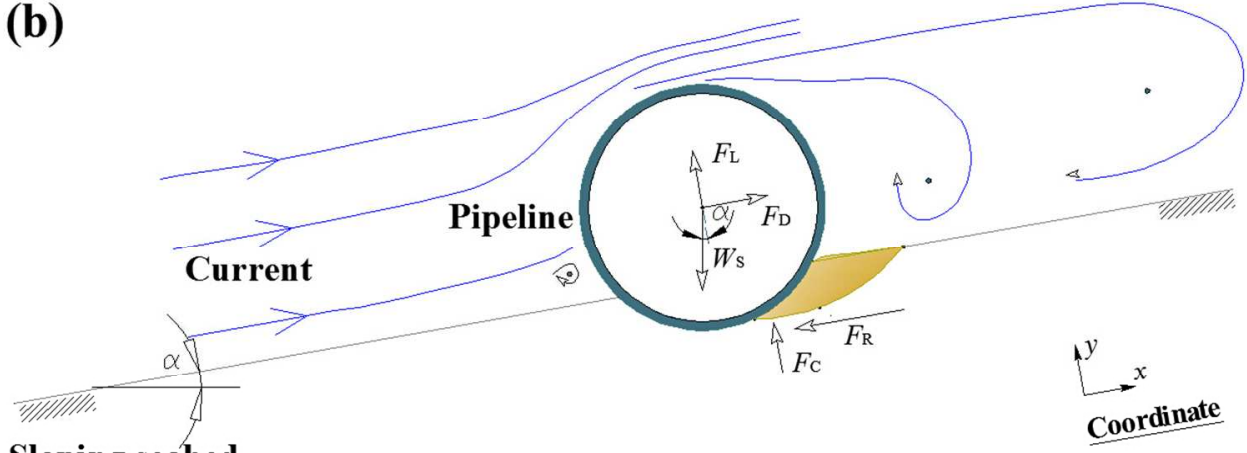

Sloping seabed

Fig 1

$343 \times 303 \mathrm{~mm}(96 \times 96$ DPI) 

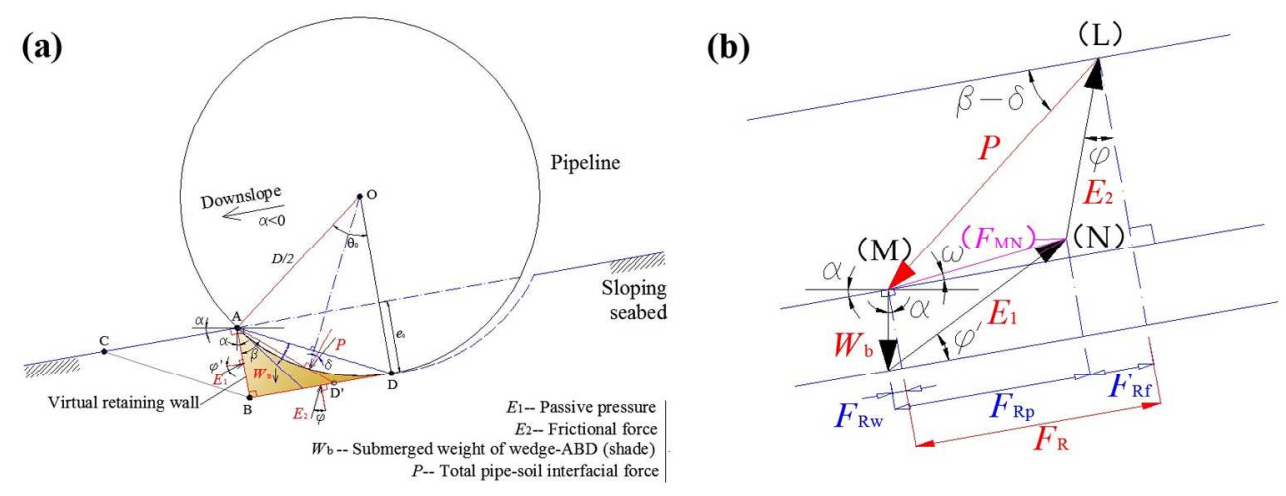

Fig 2

$455 \times 175 \mathrm{~mm}(96 \times 96 \mathrm{DPI})$ 

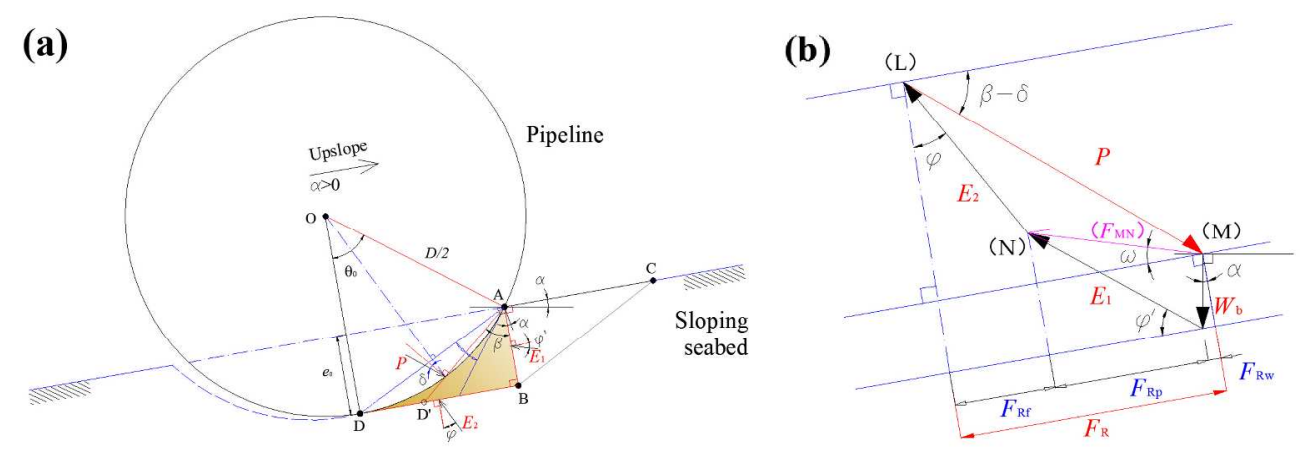

Fig 3

$635 \times 212 \mathrm{~mm}(96 \times 96 \mathrm{DPI})$ 


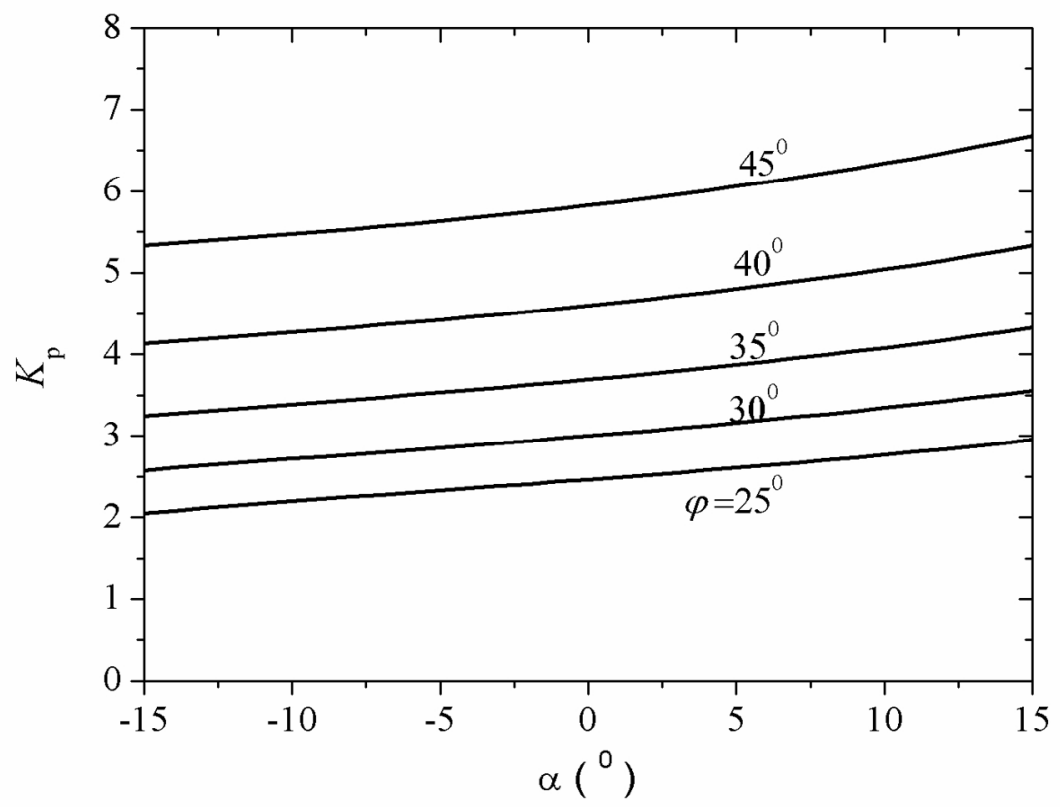

Fig 4 $289 \times 202 \mathrm{~mm}(150 \times 150$ DPI $)$ 


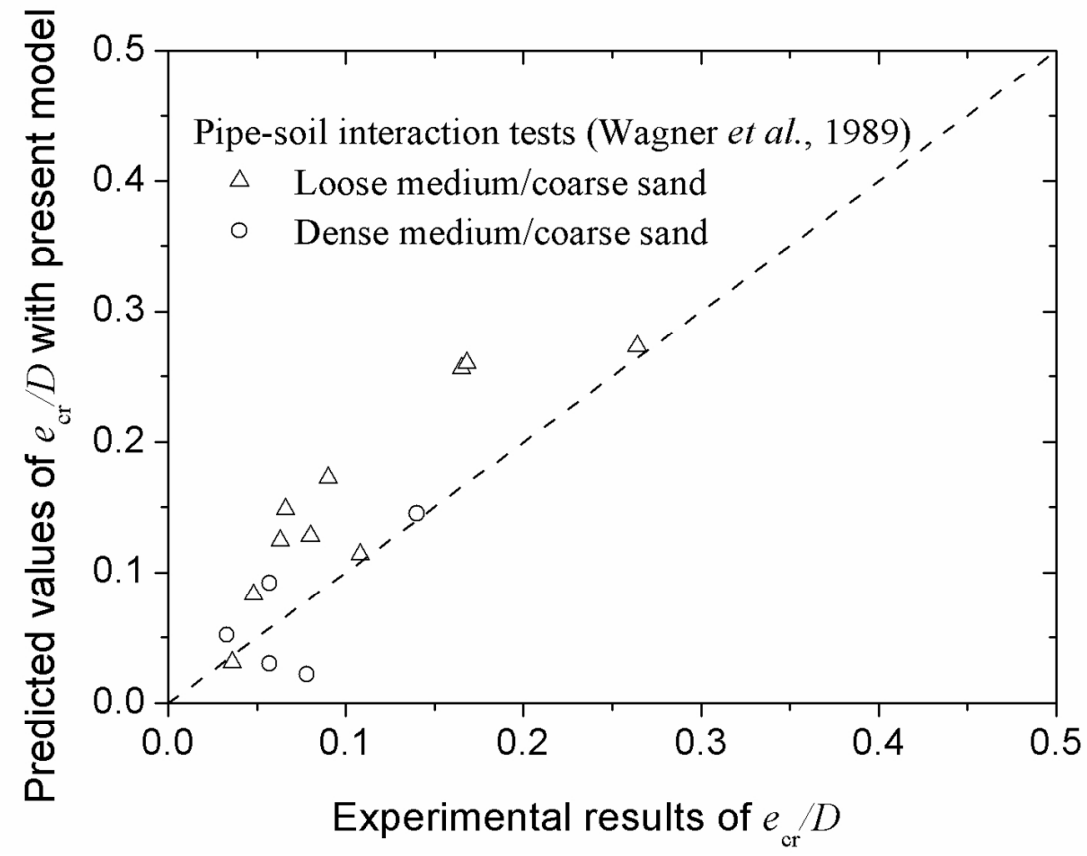

Fig 5

$289 \times 202 \mathrm{~mm}(150 \times 150 \mathrm{DPI})$ 

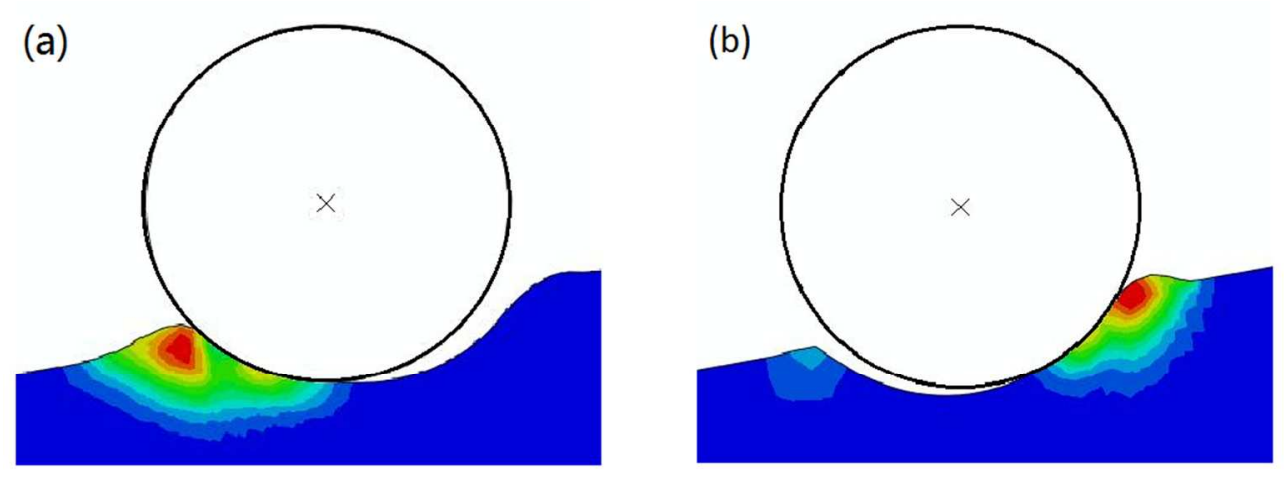

Fig 6

$288 \times 110 \mathrm{~mm}(96 \times 96 \mathrm{DPI})$ 

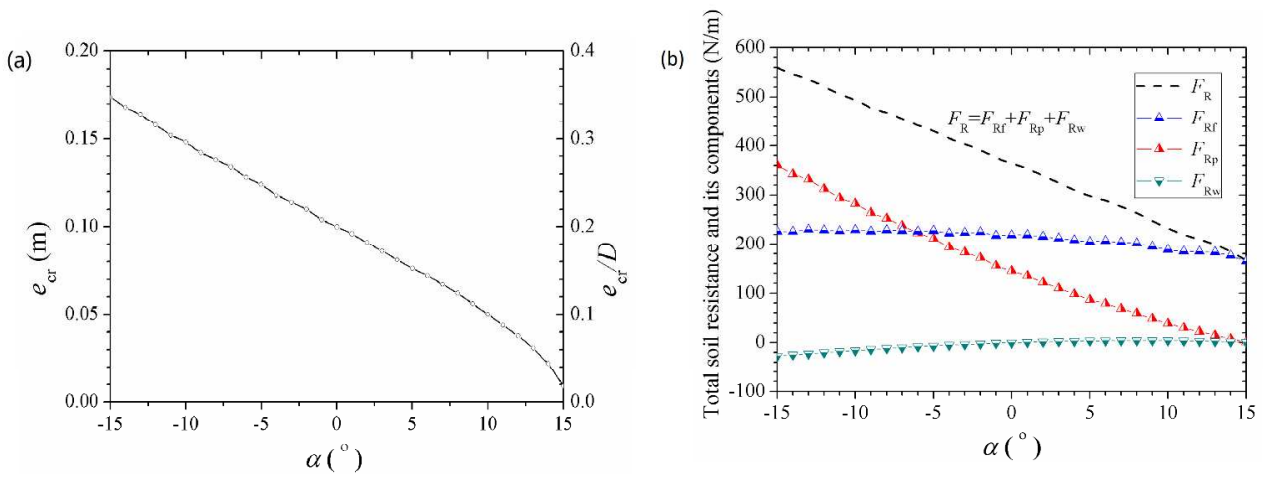

Fig 7

$678 \times 258 \mathrm{~mm}(150 \times 150 \mathrm{DPI})$ 
Table 1. Test results by Wagner et al. (1989) and predictions with the present model for pipe-soil interactions on flat sand-beds.

\begin{tabular}{|c|c|c|c|c|c|c|c|c|c|c|}
\hline \multirow[b]{2}{*}{ Test No. } & \multirow{2}{*}{$\begin{array}{l}\varphi \\
\left({ }^{0}\right)\end{array}$} & \multirow{2}{*}{$\begin{array}{c}\gamma^{\prime} \\
(\mathrm{kN} / \mathrm{m})\end{array}$} & \multirow{2}{*}{$\begin{array}{c}D \\
(\mathrm{~m})\end{array}$} & \multirow{2}{*}{$\begin{array}{c}W_{\mathrm{s}} \\
(\mathrm{kN} / \mathrm{m})\end{array}$} & \multicolumn{3}{|c|}{ Test Results } & \multicolumn{3}{|c|}{ Predictions with present model } \\
\hline & & & & & $e_{\mathrm{cr}} / D$ & $\begin{array}{r}W_{\mathrm{S}}-F_{\mathrm{L}} \\
(\mathrm{kN} / \mathrm{m})\end{array}$ & $\begin{array}{c}F_{\mathrm{R}} \\
(\mathrm{kN} / \mathrm{m})\end{array}$ & $e_{\mathrm{cr}} / D$ & $\begin{array}{c}F_{\mathrm{Rp}} \\
(\mathrm{kN} / \mathrm{m})\end{array}$ & $\begin{array}{c}F_{\mathrm{Rf}} \\
(\mathrm{kN} / \mathrm{m})\end{array}$ \\
\hline LMS-1 & 35 & 8.6 & 1.0 & 3.0 & 0.08 & 1.60 & 1.67 & 0.12 & 0.26 & 1.41 \\
\hline LMS-2 & 35 & 8.6 & 0.5 & 0.8 & 0.07 & 0.50 & 0.44 & 0.14 & 0.07 & 0.37 \\
\hline LMS-3 & 35 & 8.6 & 1.0 & 2.0 & 0.05 & 1.25 & 1.00 & 0.08 & 0.09 & 0.91 \\
\hline LMS-4 & 35 & 8.6 & 1.0 & 1.0 & 0.03 & 0.74 & 0.54 & 0.03 & 0.02 & 0.52 \\
\hline LMS-5 & 35 & 8.6 & 1.0 & 3.0 & 0.17 & 1.39 & 1.98 & 0.25 & 0.85 & 1.13 \\
\hline LMS-6 & 35 & 8.6 & 1.0 & 3.0 & 0.17 & 1.26 & 2.12 & 0.26 & 0.96 & 1.16 \\
\hline LMS-7 & 35 & 8.6 & 0.5 & 0.8 & 0.09 & 0.51 & 0.48 & 0.17 & 0.09 & 0.39 \\
\hline LMS-8 & 35 & 8.6 & 1.0 & 2.0 & 0.07 & 1.15 & 1.07 & 0.12 & 0.20 & 0.87 \\
\hline LMS-9 & 35 & 8.6 & 1.0 & 3.0 & 0.26 & 1.46 & 2.16 & 0.27 & 0.97 & 1.19 \\
\hline LMS-10 & 35 & 8.6 & 1.0 & 1.0 & 0.10 & 0.72 & 0.81 & 0.11 & 0.23 & 0.58 \\
\hline DMS-1 & 40 & 9.6 & 1.0 & 3.0 & 0.05 & 1.84 & 1.57 & 0.03 & 0.04 & 1.53 \\
\hline DMS-2 & 40 & 9.6 & 1.0 & 2.0 & 0.03 & 1.30 & 1.16 & 0.05 & 0.05 & 1.11 \\
\hline DMS-3 & 40 & 9.6 & 0.5 & 0.8 & 0.07 & 0.52 & 0.44 & 0.03 & 0.02 & 0.42 \\
\hline DMS-4 & 40 & 9.6 & 1.0 & 3.0 & 0.06 & 1.65 & 1.58 & 0.09 & 0.14 & 1.44 \\
\hline DMS-5 & 40 & 9.6 & 1.0 & 3.0 & 0.14 & 1.59 & 1.79 & 0.15 & 0.36 & 1.43 \\
\hline
\end{tabular}

Note: "LMS" and "DMS" refer to the Loose Medium/coarse Sand $\left(D_{\mathrm{r}} \approx 0.3\right)$ and the Dense

Medium/coarse Sand $\left(D_{\mathrm{r}} \approx 0.7\right)$ respectively in the tests by Wagner et al. (1989). 
Table 2. Input data for case study of the slope angle effect on pipeline lateral instability

\begin{tabular}{|l|l|l|}
\hline Input parameters & Values & Note \\
\hline Flow velocity of the ocean current $U(\mathrm{~m} / \mathrm{s})$ & 1.5 & \\
\hline Pipeline diameter $D(\mathrm{~m})$ & 0.5 & \\
\hline Reynolds number Re & $0.5 \times 10^{6}$ & \\
\hline Drag force coefficient $C_{\mathrm{D}}$ & 0.65 & (Jones,1978) \\
\hline Lift force coefficient $C_{\mathrm{L}}$ & 0.86 & (Jones,1978) \\
\hline Drag force on the pipeline $F_{\mathrm{D}}(\mathrm{kN} / \mathrm{m})$ & 0.366 & eq. (2a) \\
\hline Lift force on the pipeline $F_{\mathrm{L}}(\mathrm{kN} / \mathrm{m})$ & 0.484 & eq. (2b) \\
\hline Submerged weight of the pipeline $W_{\mathrm{s}}(\mathrm{kN} / \mathrm{m})$ & 0.75 & \\
\hline Effective unit weight of the sands $\gamma^{\prime}\left(\mathrm{kN} / \mathrm{m}^{3}\right)$ & 9.6 & \\
\hline Internal friction angle of the sands $\varphi\left({ }^{0}\right)$ & $35^{0}$ & \\
\hline Examined range of slope angle $\alpha\left({ }^{0}\right)$ & $-15^{0} \sim 15^{0}$ & \\
\hline Variation of passive pressure coefficients $K_{\mathrm{p}}$ & $3.25 \sim 4.33$ & Fig. 4 \\
\hline
\end{tabular}

